\title{
Influence of oxygen tension on myocardial performance. Evaluation by tissue Doppler imaging
}

\author{
Ole Frøbert ${ }^{* 1,2}$, Jacob Moesgaard ${ }^{1}$, Egon Toft ${ }^{3}$, Steen Hvitfeldt Poulsen ${ }^{4}$ and \\ Peter Søgaard ${ }^{1}$
}

Address: ${ }^{1}$ Department of Cardiology, Center for Cardiovascular Research, Aalborg Hospital, Aarhus University Hospital, Denmark, ${ }^{2}$ Institute of Pharmacology, University of Aarhus, Denmark, ${ }^{3}$ Center for Model-based Medical Decision Support Systems, Department of Health Science and Technology, Aalborg University, Aalborg, Denmark and ${ }^{4}$ Skejby University Hospital, Aarhus, Denmark

Email: Ole Frøbert* - frobert@dadlnet.dk; Jacob Moesgaard - jm@doktor.dk; Egon Toft - ET@healthntech.dk; Steen Hvitfeldt Poulsen - steen.hvitfeldt@dadlnet.dk; Peter Søgaard - psogaard@dadlnet.dk

* Corresponding author

Published: 02 November 2004

Cardiovascular Ultrasound 2004, 2:22 doi:10.1 |86//476-7|20-2-22
Received: 26 August 2004

Accepted: 02 November 2004

This article is available from: http://www.cardiovascularultrasound.com/content/2/I/22

(c) 2004 Frøbert et al; licensee BioMed Central Ltd.

This is an Open Access article distributed under the terms of the Creative Commons Attribution License (http://creativecommons.org/licenses/by/2.0), which permits unrestricted use, distribution, and reproduction in any medium, provided the original work is properly cited.

\begin{abstract}
Background: Low $\mathrm{O}_{2}$ tension dilates coronary arteries and high $\mathrm{O}_{2}$ tension is a coronary vasoconstrictor but reports on $\mathrm{O}_{2}$-dependent effects on ventricular performance diverge. Yet oxygen supplementation remains first line treatment in cardiovascular disease. We hypothesized that hypoxia improves and hyperoxia worsens myocardial performance.
\end{abstract}

Methods: Seven male volunteers (mean age $38 \pm 3$ years) were examined with echocardiography at respiratory equilibrium during: I) normoxia $\left(\approx 21 \% \mathrm{O}_{2}, 79 \% \mathrm{~N}_{2}\right)$, 2) while inhaling a hypoxic gas mixture $\left(\approx 11 \% \mathrm{O}_{2}, 89 \% \mathrm{~N}_{2}\right)$, and 3) while inhaling $100 \% \mathrm{O}_{2}$. Tissue Doppler recordings were acquired in the apical 4-chamber, 2-chamber, and long-axis views. Strain rate and tissue tracking displacement analyses were carried out in each segment of the 16-segment left ventricular model and in the basal, middle and apical portions of the right ventricle.

Results: Heart rate increased with hypoxia $(68 \pm 4$ bpm at normoxia vs. $79 \pm 5$ bpm, $P<0.00$ I) and decreased with hyperoxia ( $59 \pm 5 \mathrm{bpm}, \mathrm{P}<0.00 \mathrm{I}$ vs. normoxia). Hypoxia increased strain rate in four left ventricular segments and global systolic contraction amplitude was increased (normoxia: $9.76 \pm 0.4 \mathrm{I}$ vs hypoxia: $10.87 \pm 0.42, \mathrm{P}<0.00 \mathrm{I}$ ). Tissue tracking displacement was reduced in the right ventricular segments and tricuspid regurgitation increased with hypoxia $(7.5 \pm 1.9 \mathrm{mmHg}$ vs. $33.5 \pm 1.8 \mathrm{mmHg}, \mathrm{P}<0.00 \mathrm{I})$. The TEl index and E/E' did not change with hypoxia. Hyperoxia reduced strain rate in 10 left ventricular segments, global systolic contraction amplitude was decreased $(8.83 \pm 0.38, P<0.001$ vs. normoxia) while right ventricular function was unchanged. The spectral and tissue Doppler TEl indexes were significantly increased but E/E' did not change with hyperoxia.

Conclusion: Hypoxia improves and hyperoxia worsens systolic myocardial performance in healthy male volunteers. Tissue Doppler measures of diastolic function are unaffected by hypoxia/ hyperoxia which support that the changes in myocardial performance are secondary to changes in vascular tone. It remains to be settled whether oxygen therapy to patients with heart disease is a consistent rational treatment. 


\section{Introduction}

Low oxygen tension dilates coronary arteries and high oxygen tension is a coronary vasoconstrictor. Yet oxygen supplementation remains first line treatment in cardiovascular disease states such as myocardial infarction and pulmonary oedema.

Endothelium-dependent vasodilation is reduced in patients with ischemic heart disease [1] and such patients are believed to have a reduced ability to counteract the circulatory consequences of systemic (air line travel, high altitude stay) and regional (coronary artery stenosis) hypoxia. Spontaneous nocturnal hypoxia with desaturation for hours is a frequent phenomenon in patients with severe coronary artery disease [2]. Left atrial, left ventricular (LV), and right ventricular (RV) end-systolic diameter fall during simulated extreme altitude [3] and during moderate altitude exposure [4]. There is controversy concerning myocardial performance during hypoxia; improvement [4], no change [3,5,6]. and worsening [7] of left ventricular systolic function, have been described. One study looked at diastolic function expressed as E/A ratio and found a reduction with hypoxia [3].

Hyperoxia, a condition in which the total oxygen content of the body is increased above that normally existing at sea level, is associated with impairment of cardiac relaxation and increased left ventricular filling pressures in patients with and without congestive heart failure [8].

Tissue Doppler imaging (TDI) objectively derives measurements of contraction and relaxation velocities directly from the myocardium and thus yields information not previously accessible by echocardiography [9]. We used TDI to study myocardial performance in healthy volunteers and we hypothesized that hypoxia increases and hyperoxia reduces myocardial performance.

\section{Material and Methods Subjects}

Seven healthy men, (age 25-46 (mean 38) years) completed the study. All subjects were normotensive, nonsmokers, on no medication, had a normal left ventricular function by 2-D echocardiography, and had no family history of ischemic heart disease. The local ethical committee approved the study.

\section{Ventilation system}

We used a system consisting of a ventilator, a gas analyser with pulse oximeter, and a computer. Computer programs control the experimental procedure and continuously collect data from the ventilator and gas analyser [10].

\section{Echocardiography}

Echocardiography was performed from the apical acoustic window. Tissue Doppler recordings were acquired as digital loops in the apical 4-chamber, 2-chamber, and longaxis views [9]. To avoid aliasing, the settings of the ultrasound equipment and colour-coded area were adjusted to obtain the highest possible frame rate. We measured peak strain in the 16-segment left ventricular model and in 3 segments in the right. From the color-coded tissue tracking image, the motion amplitude toward the apex in systole was recorded in each segment. The global systolic contraction amplitude (GSCA) was calculated as the average shortening amplitude of all 16 segments. The peak $\mathrm{E}$ velocity was obtained by pulsed Doppler measurements of the mitral inflow at the tip of the mitral leaflets. We further assessed isovolumetric acceleration, TEI index (spectral and TDI), tricuspid regurgitation and pulmonary ejection time. The tissue E' velocity was obtained by Tissue Doppler at the lateral mitral annulus. E/E' has been proposed as a tool for assessing LV filling pressures that combines the influence of transmitral driving pressure and myocardial relaxation [11]. The TEI index (spectral or TDI), a combined measure of systolic and diastolic function, was assessed by Doppler time intervals from the mitral inflow and LV outflow tract or the time intervals were obtained by TDI at the lateral mitral annulus. The TEI index was calculated by a-b/b where the time interval "a" was measured from cessation to onset of mitral inflow and the time interval " $\mathrm{b}$ " was the duration of the LV outflow velocity profile. To minimize the variability of the measurements, all ECHO recordings were performed and analyzed in a blinded fashion by the same author (P.S.).

\section{Study protocol}

TDI was performed when the subjects had rested for 15 minutes breathing room air $\left(\mathrm{SpO}_{2} 97.9 \pm 0.1 \%\right)$, after 5 minutes of respiratory equilibrium during hypoxia $\left(\mathrm{SpO}_{2}\right.$ $77.6 \pm 1.2 \%)$, and after 5 minutes of respiratory equilibrium during hyperoxia $\left(\mathrm{SpO}_{2} 99.0 \pm 0.2 \%\right)$. Heart rate was continuously recorded on computer by means of the pulse oximeter. Blood pressure was measured once during each of the three respiratory steady state situations by an automatic blood pressure measuring device based on the oscillometric method.

\section{Statistical analysis}

All data are presented as mean \pm SEM. Comparisons of the responses to changes in $\mathrm{F}_{\mathrm{i}} \mathrm{O}_{2}$ (normoxia, hypoxia and hyperoxia) were made with a one-way repeated-measures analysis of variance. The Student-Newman-Keuls test was used post hoc to identify pairwise differences. Differences were considered statistically significant when $\mathrm{P}<0.05$. 


\section{Results}

\section{Respiratory parameters and hemodynamics}

$\mathrm{FiO}_{2}$ and $\mathrm{FeO}_{2}$ decreased with hypoxia and increased with $100 \%$ oxygen breathing (table 1 ). $\mathrm{FeCO}_{2}$ and tidal volume were unchanged in all three test situations, reflecting that the subjects were in respiratory steady state. There was a small, but statistically significant decrease in respiratory rate from normoxia to hypoxia, which might reflect that the subjects were more accustomed to the test situation at this stage.

There was a significant increase in heart rate with hypoxia and a decrease with hyperoxia (figure 1). Neither systolic $(126 \pm 6,123 \pm 8,122 \pm 12 \mathrm{mmHg}$, respectively, $\mathrm{P}=\mathrm{ns})$ nor diastolic blood pressure $(80 \pm 5,78 \pm 8,81 \pm 6$ $\mathrm{mmHg}$, respectively, $\mathrm{P}=\mathrm{ns}$ ) changed significantly with test situation.

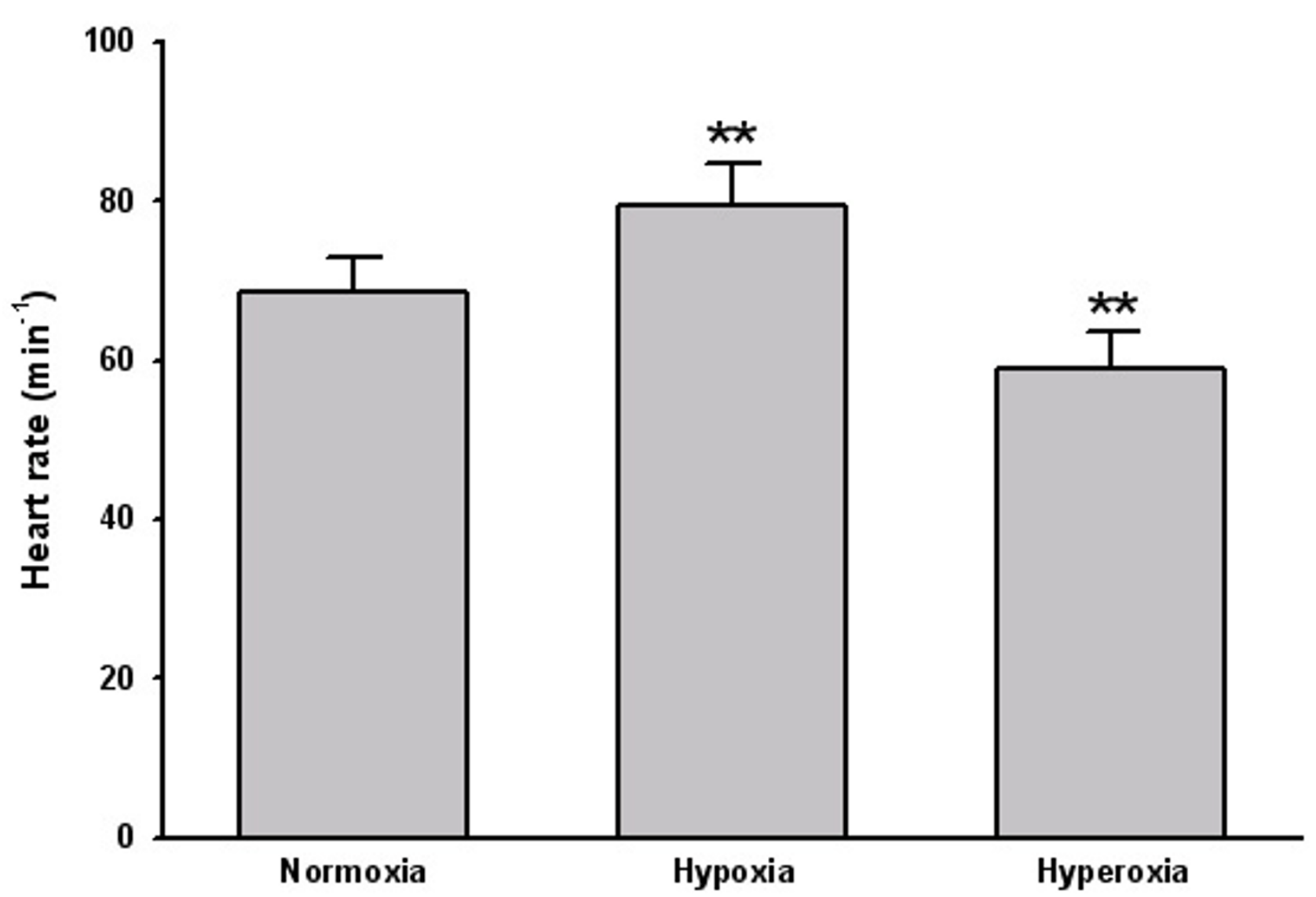

Figure I

Bar graph depicting heart rate during normoxia, hypoxia and hyperoxia. $* * P<0.0$ I vs. normoxia.

TDI and spectral echocardiography, hypoxia

A significant increase in strain rate was found in 4 segments (figure 2). GSCA increased with hypoxia (9.76 \pm 0.41 vs. $10.87 \pm 0.42, \mathrm{P}<0.001$, figure 3$)$. Tissue tracking displacement was reduced in all three right ventricular segments (figure 4) and systolic tricuspid regurgitation increased with hypoxia (figure 5). The TEI index (spectral or TDI) and E/E' did not change with hypoxia.

\section{TDI and spectral echocardiography, hyperoxia}

Hyperoxia worsened left ventricular function. Strain rate was reduced in 10 segments (figure 2) with preponderance in the lateral and anterior segments. GSCA was reduced $(8.83 \pm 0.38, \mathrm{P}<0.001$ vs. normoxia). Tissue tracking displacement did not change in the right ventricular segments (figure 4) and systolic tricuspid regurgitation was unchanged compared with normoxia (figure 


\section{Myoc ardial segm ents}

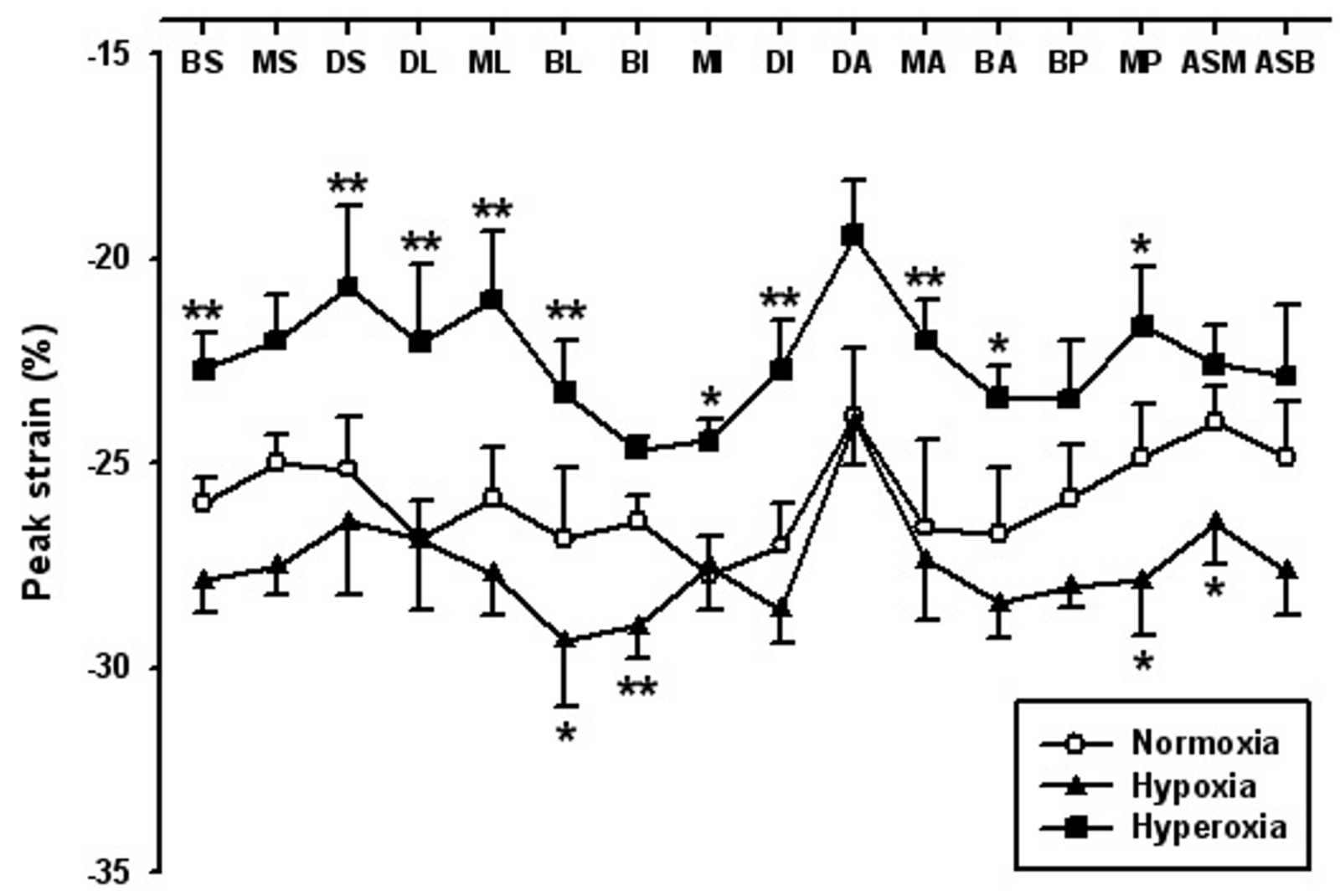

Figure 2

Comparison of peak systolic strain in the 16-segment left ventricular model illustrating the effects of hypoxia and hyperoxia. A, Anterior; $B$, basal; $D$, distal; I, inferior; $L$, lateral; $M$, mid; $P$, posterior; $S$, septal. $* P<0.05$, ** $P<0.0$ l vs. normoxia.

$5)$ ). The TDI TEI index was significantly increased with hyperoxia $(0.32 \pm 0.04$ vs. $0.45 \pm 0.05, \mathrm{P}<0.001)$ and the spectral TEI index showed similar changes. E/E' did not change with hyperoxia.

\section{Discussion}

The main findings of the present study of healthy volunteers are: 1) hypoxia increased strain rate and tissue tracking displacement. 2) Hypoxia increased tricuspid regurgitation and reduced right ventricular tissue tracking displacement. 3) Hyperoxia reduced strain rate and tissue tracking displacement and increased the TEI index. The novelty of our findings, when compared to the literature, is the demonstration that longitudinal myocardial function, and thus the function of the subendocardium, is sensitive to moderate changes in inspired oxygen.

Patients with ischemic heart disease and heart failure frequently encounter hypoxia but the consequences of hypoxia on left ventricular function remain a matter of controversy, in part because of differences in methodology and the measured parameters. In early studies using roentgenkymograms [12] and dye injection [13] hypoxia was shown to increase cardiac output at rest despite 


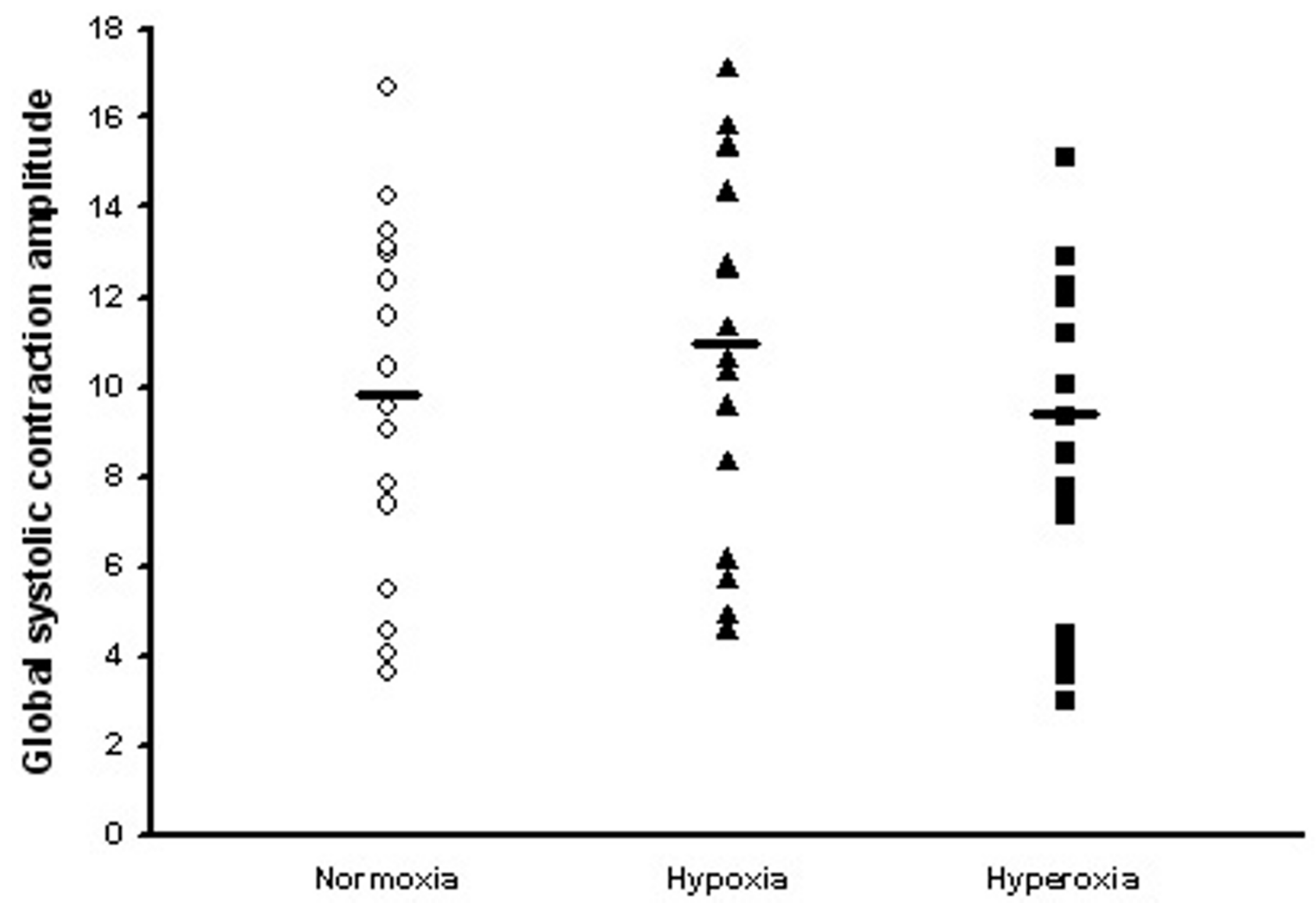

Figure 3

Tissue tracking score index on the basis of the 16-segment left ventricular model illustrating the effects of hypoxia and hyperoxia.

reduced [13] or unchanged [12] stroke volume. The authors explained the increase in cardiac output by increased heart rate $[12,13]$ Myocardial blood flow in the left and right ventricles increased at high altitude in dogs studied with radioactive microspheres [14] and in healthy controls using positron emission tomography [15]. In a study using M-mode echocardiography at high altitude [4] percent fractional shortening and velocity of circumferential fiber shortening remained normal while LV isovolumetric contraction time shortened. Echocardiography was also employed in a simulated ascent of Mount Everest [3] and an insignificant increase in fractional shortening and ejection fraction was found. It is generally accepted that right-sided pressures increase with hypoxia $[3,14] \mathrm{We}$ speculate that the improvement in tissue tracking displacement in our study reflects the systemic vasodilation which is another consequence of hypoxia [16]. On the other hand, RV-systolic function decreased which is likely to be correlated to the increased systolic pulmonary pressure reflecting the increased pulmonary vascular resistance during hypoxia.

Hemoglobin saturation in healthy persons increase very little from breathing room air to breathing $100 \%$ oxygen. Nevertheless, profound cardiovascular effects were found. This is probably because of an anticipated increase in oxygen dissolved into plasma from $0.32 \%$ to $2.09 \%$ [17]. Hyperoxia is a possible product of oxygen therapy when administered to patients with heart disease during acute illness. Hyperoxia reduces cardiac output as documented with roentgenkymograms [12], dye injection [18,19]., echocardiography [20] heart catheterisation [8] and 


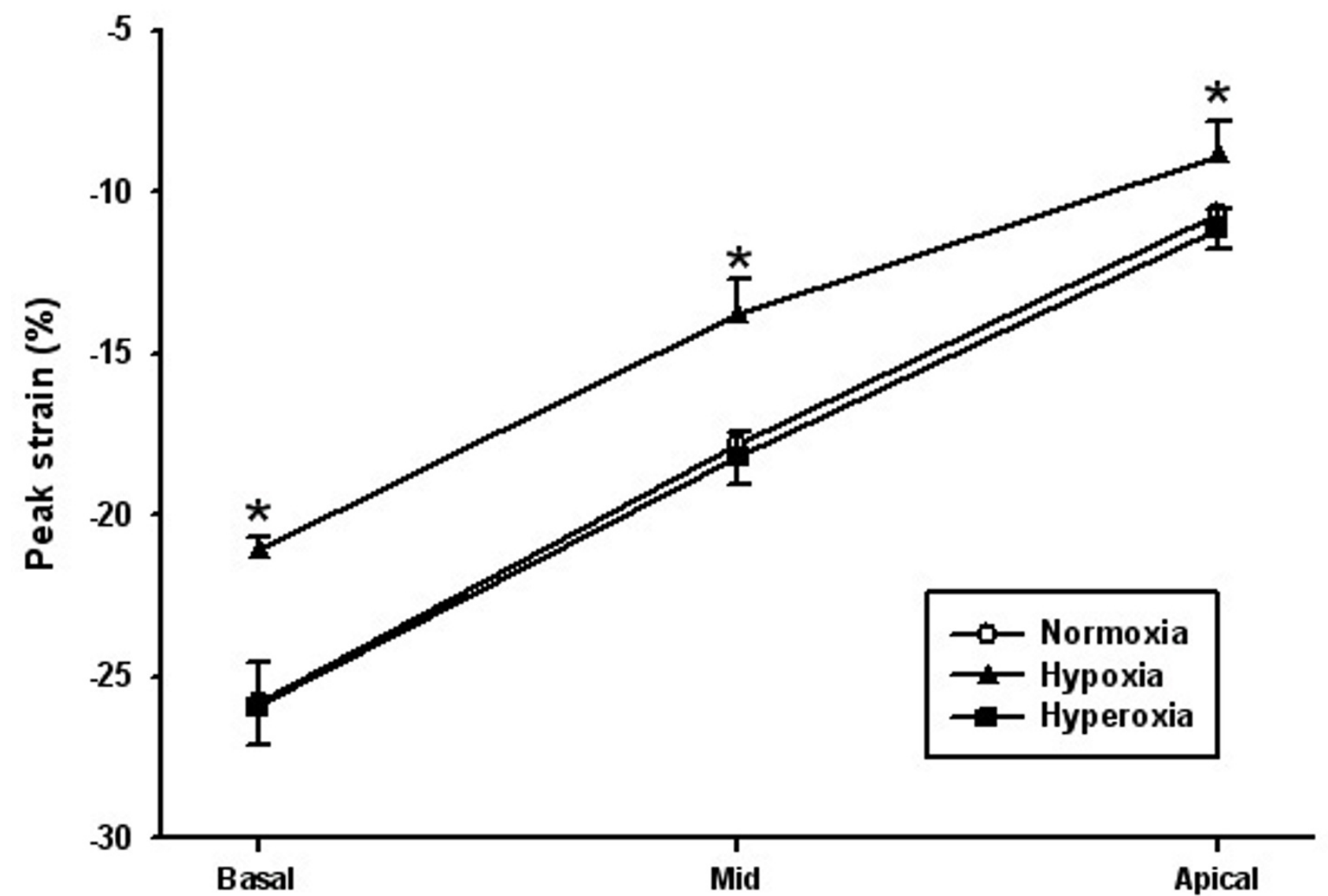

\section{Myocardial segm ents}

\section{Figure 4}

Comparison of peak systolic strain in the right ventricle model illustrating the effects of hypoxia and hyperoxia. * $\mathrm{P}<0.05$.

indirectly by measurement of isometric systolic tension by means of strain gauge in dogs [21]. Reduced cardiac output with hyperoxia has even been demonstrated in patients with myocardial infarction using dye injection [22]. Some of the reduction in cardiac output may be explained by the observation that hyperoxia reduces heart rate as seen in our study and previously [19,23-25] Reduced heart rate is, however, not an entirely consistent finding $[8,20,22,26]$ but in these four studies this could be because of high sympathetic tone (stay in a hyperbaric chamber [20], acute myocardial infarction [22], open heart surgery [26], heart catheterisation [8]). We found that heart rate increased with hypoxia and decreased with hyperoxia. This might have affected our measures of LV systolic and diastolic function but we consider this unlikely on the basis of our previous studies $[11,27]$ demonstrating that TEI index, strain rate and the tissue tracking was unrelated to heart rate. During hypoxia as well as hyperoxia no change in LV filling pressure was noted as the $\mathrm{E} / \mathrm{E}^{\prime}$ ratio was unchanged. The individual parameters in the $\mathrm{E} / \mathrm{E}^{\prime}$ ratio are known to be influenced by heart rate but as a ratio it seems independent of heart rate and load conditions [11,27]. Therefore, we did not perform any adjustments for heart rate in the evaluation of LV diastolic function.

Because of the finding of no change [19] or a discrete rise $[18,22]$ in blood pressure, a reduction in cardiac output results in an increased systemic vascular resistance during hyperoxia $[18,19,22]$ Regardless of the fact that 


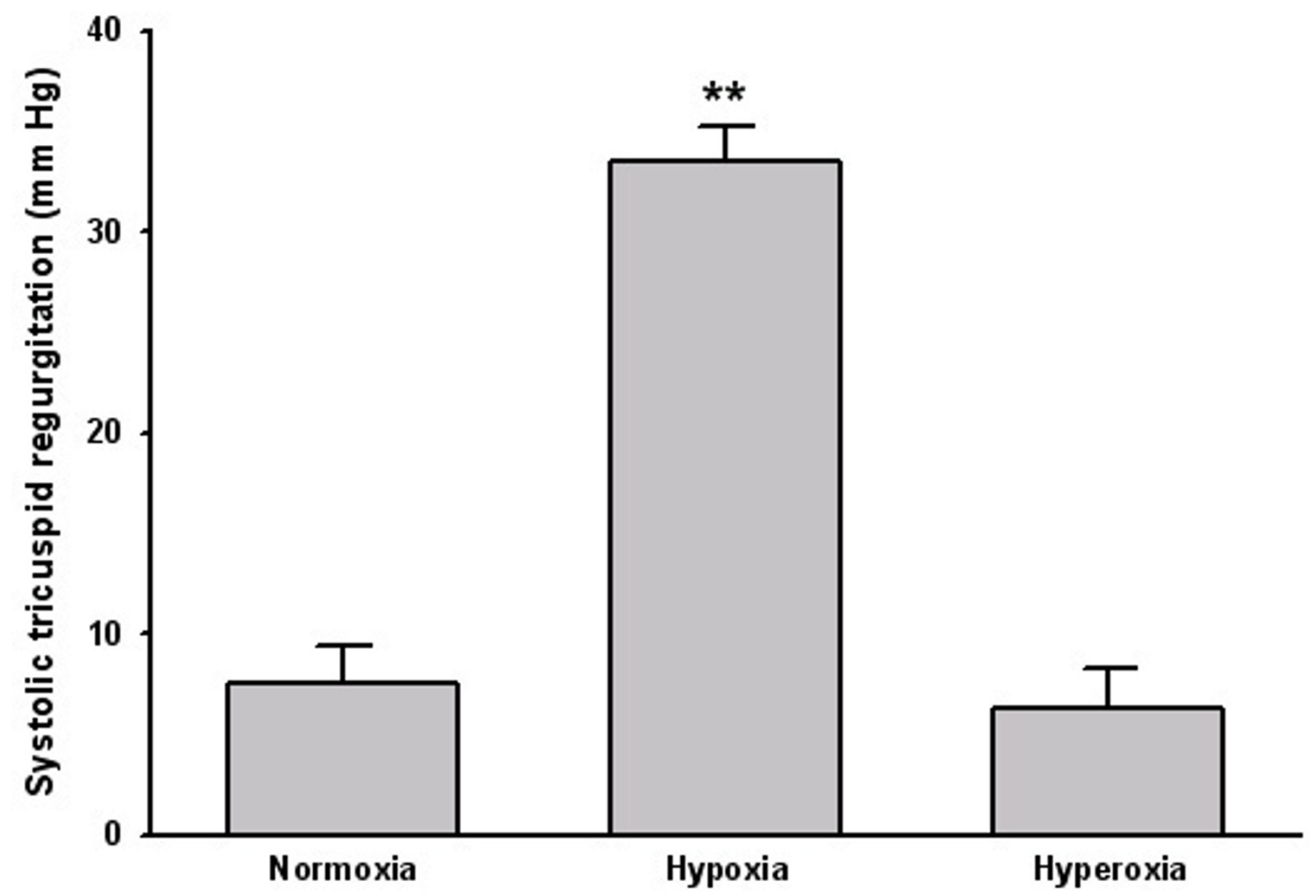

Figure 5

Bar graph depicting systolic tricuspid regurgitation during normoxia, hypoxia and hyperoxia. $* * P<0.01$ vs. normoxia.

sympathetic tone may be affected by hyperoxia, even after complete sympathetic blockade myocardial contractile force remains reduced [26]. In the present study both tissue tracking displacement and strain rate worsened during hyperoxia. It seems plausible that this deterioration could be explained by systemic vasoconstriction [21] increasing afterload.

In conclusion, hypoxia improves and hyperoxia worsens systolic myocardial performance in healthy male volunteers. TDI measures of diastolic function are unaffected by hypoxia/hyperoxia which support that the changes in myocardial performance are secondary to changes in vascular tone. It remains to be settled whether oxygen therapy to patients with heart disease is a rational treatment that may sometimes be harmful or whether supplemental oxygen consistently results in an overall gain in delivered oxygen.

\section{Acknowledgements}

The study was supported by The Danish Heart Foundation (no 03-I-2-1222050), the John and Birthe Meyer Foundation, Karen Elise Jensens Fond, the Novo Nordisk Foundation, and the Danish Medical Research Council.

\section{References}

I. Adams MR, McCredie R, Jessup W, Robinson J, Sullivan D, Celermajer $D S:$ Oral L-arginine improves endothelium-dependent dilatation and reduces monocyte adhesion to endothelial cells in young men with coronary artery disease. Atherosclerosis 1997, I 29:26|-269.

2. Smith HL, Sapsford DJ, Delaney ME, Jones JG: The effect on the heart of hypoxaemia in patients with severe coronary artery disease. Anaesthesia 1996, 51:211-218.

3. Boussuges A, Molenat F, Burnet H, Cauchy E, Gardette B, Sainty JM, Jammes Y, Richalet JP: Operation Everest III (Comex '97): modifications of cardiac function secondary to altitude-induced 
hypoxia. An echocardiographic and Doppler study. Am J Respir Crit Care Med 2000, 161:264-270.

4. Fowles RE, Hultgren $\mathrm{HN}$ : Left ventricular function at high altitude examined by systolic time intervals and M-mode echocardiography. Am J Cardiol 1983, 52:862-866.

5. Alexander JK, Grover RF: Mechanism of reduced cardiac stroke volume at high altitude. Clin Cardiol 1983, 6:30I-303.

6. Reeves JT, Groves BM, Sutton JR, Wagner PD, Cymerman A, Malconian MK, Rock PB, Young PM, Houston CS: Operation Everest II: preservation of cardiac function at extreme altitude. J Appl Physiol 1987, 63:531-539.

7. Maruyama J, Tobise K, Kawashima E: The effect of acute hypoxia on left ventricular function with special reference to diastolic function - an analysis using ultrasonic method. Jpn Circ J 1992, 56:998-10II.

8. Mak S, Azevedo ER, Liu PP, Newton GE: Effect of hyperoxia on left ventricular function and filling pressures in patients with and without congestive heart failure. Chest 200 I, I 20:467-473.

9. Isaaz K: Tissue Doppler imaging for the assessment of left ventricular systolic and diastolic functions. Curr Opin Cardiol 2002, 17:431-442.

10. Rees SE, Kjaergaard S, Perthorgaard P, Malczynski J, Toft E, Andreassen $S$ : The automatic lung parameter estimator (ALPE) system: non-invasive estimation of pulmonary gas exchange parameters in 10-I 5 minutes. J Clin Monit Comput 2002, 1 7:43-52.

II. Poulsen SH, Nielsen JC, Andersen HR: The influence of heart rate on the Doppler-derived myocardial performance index. J Am Soc Echocardiogr 2000, I3:379-384.

12. Keys A, Stapp JP, Violante A: Responses in size, output and efficiency of the human heart to acute alteration in the composition of inspired air. Am J Physiol 2004, I38:763-77I.

13. Asmussen $E$, Nielsen $M$ : The cardiac output in rest and work at low and high oxygen pressures. Acta Physiol Scand 1955, 35:73-83.

14. Jones DP, Damiano R, Cox JL, Wolfe WG: The effect of altitudeinduced hypoxia on regional myocardial blood flow. J Thorac Cardiovasc Surg 1981, 82:216-220.

15. Wyss CA, Koepfli P, Fretz G, Seebauer M, Schirlo C, Kaufmann PA: Influence of altitude exposure on coronary flow reserve. Circulation 2003, 108: 1202-1207.

16. Taggart MJ, Wray S: Hypoxia and smooth muscle function: key regulatory events during metabolic stress. J Physiol 1998, 509(Pt 2):315-325.

17. Grim PS, Gottlieb LJ, Boddie A, Batson E: Hyperbaric oxygen therapy. JAMA 1990, 263:2216-2220.

18. Daly W], Bondurant S: Effects of oxygen breathing on the heart rate, blood pressure, and cardiac index of normal men - resting, with reactive hyperemia, and after atropine. J Clin Invest | $962,4|:| 26-\mid 32$.

19. Kenmure AC, Murdoch WR, Hutton I, Cameron AJ: Hemodynamic effects of oxygen at $I$ and 2 Ata pressure in healthy subjects. J Appl Physiol 1972, 32:223-226.

20. Molenat F, Boussuges A, Grandfond A, Rostain JC, Sainty JM, Robinet C, Galland F, Meliet JL: Hemodynamic effects of hyperbaric hyperoxia in healthy volunteers: An Echocardiographic and Doppler study. Clin Sci (Lond) 2003.

21. Crawford P, Good PA, Gutierrez E, Feinberg JH, Boehmer JP, Silber $\mathrm{DH}$, Sinoway LI: Effects of supplemental oxygen on forearm vasodilation in humans. J Appl Physiol 1997, 82:160I-1606.

22. Kenmure AC, Murdoch WR, Beattie AD, Marshall JC, Cameron AJ: Circulatory and metabolic effects of oxygen in myocardial infarction. Br Med J 1 968, 4:360-364.

23. Benedict FG, Higgins $\mathrm{HL}$ : Effects on men at rest of breathing oxygen-rich gas mixtures. Am J Physiol I9II, 28: I-28.

24. Barratt-Boyes BG, Wood EH: Cardiac output and related measurements and pressure values in the right heart and associated vessels, together with an analysis of the hemo-dynamic response to the inhalation of high oxygen mixtures in healthy subjects. J Lab Clin Med 1958, 5 I:72-90.

25. Alveryd A, Brody S: Cardiovascular and respiratory changes in man during oxygen breathing. Acta Physiol Scand 1948, 15:140-149.

26. Daniell HB, Bagwell EE: Effects of high oxygen on coronary flor and heart force. Am J Physiol 1968, 214:1454-1459.

27. Andersen $\mathrm{NH}$, Poulsen $\mathrm{SH}$ : Evaluation of the longitudinal contraction of the left ventricle in normal subjects by Doppler tissue tracking and strain rate. J Am Soc Echocardiogr 2003, 16:716-723.
Publish with Biomed Central and every scientist can read your work free of charge

"BioMed Central will be the most significant development for disseminating the results of biomedical research in our lifetime. "

Sir Paul Nurse, Cancer Research UK

Your research papers will be:

- available free of charge to the entire biomedical community

- peer reviewed and published immediately upon acceptance

- cited in PubMed and archived on PubMed Central

- yours - you keep the copyright 